\title{
Comparative Study of Two Congestion Management Methods for the Restructured Power Systems
}

\author{
B. V. Manikandan ${ }^{\dagger}$, S. Charles Raja*, P. Venkatesh* and Manasarani Mandala*
}

\begin{abstract}
Congestion management is one of the most challenging tasks of a system operator to ensure the operation of transmission system within operating limits. In this paper, cluster/zone method and relative electrical distance (RED) method for congestion management are compared based on the considered parameters. In the cluster/zone method, rescheduling of generation is based on user impact on congestion through the use of transmission congestion distribution factors. In the RED method, the desired proportions of generations for the desired overload relieving are obtained. Even after generation rescheduling, if congestion exists, load curtailment option is also introduced. Rescheduling cost, system cost, losses, and voltage stability parameter are also calculated and compared for the above two methods of congestion management. The results are illustrated on sample 6-bus, IEEE 30-bus, and Indian utility 69-bus systems.
\end{abstract}

Keywords: Congestion management, Transmission congestion distribution factors, Relative electrical distance, Load curtailment, Dominion, Rescheduling cost

\section{Introduction}

Congestion in a transmission system, whether in vertically integrated or unbundled electric systems, cannot be tolerated, except briefly, because this may cause cascade outages with uncontrolled loss of load. Congestion management (i.e., controlling the transmission system so that transfer limits are observed) is perhaps the fundamental transmission management problem [1]. The methods generally adopted to manage congestion include rescheduling generator outputs, supplying reactive power support, or physically curtailing transactions. System operators use the first option as much as possible and the last one as a last resort. Several techniques of congestion management have been reported [2]. Prioritization of electricity transactions and related curtailment strategies in a system where pool and bilateral/multilateral dispatches coexist was proposed in Ref. [3]. In Ref. [4], an optimal power flow(OPF)-based approach that minimizes cost of congestion and service cost is presented. A method to manage congestion based on ex ante congestion prices was proposed in Ref. [5]. A coordinating mechanism between generating companies and system operator for congestion management using Benders cuts was discussed in Ref. [6]. Detailed analysis of different congestion management techniques used in different electricity markets throughout the world and a general congestion relieving algorithm was presented in Ref. [7]. In Ref. [8], a technique was proposed for selection of par-

$\dagger$ Corresponding author: Mepco Schlenk Engineering College, Sivakasi Tamilnadu, India. (bvmani73@yahoo.com)

* Thiagarajar College of Engineering, Madurai, TamilNadu, India. (charlesrajas@tce.edu,pveee@tce.edu)

Received: September 30, 2010; Accepted: December 22, 2010 ticipating generators based on sensitivity to current flow on congested line as well as the generation bids.

In this paper, congestion management methods outlined in Refs. [9] and [10] are compared. In both methods, congestion is managed by rescheduling the generation. The motivating factors for selecting these methods for comparison are presented below.

In the cluster/zone method [9], transmission congestion distribution factors (TCDFs) based on ac power flow Jacobian sensitivity have been proposed to identify the most sensitive congestion zones/clusters for the given system. Rescheduling of generators for congestion relief is formulated as an optimization problem with the objective of minimizing the cost for rescheduling. Only specific generators in the most sensitive zone are selected for rescheduling of generation to alleviate congestion. Slack bus is not considered for rescheduling of generation because it meets additional load requirements and losses.

The relative electrical distance (RED) method [10] allocates the desired generation change over the participants/contracts based on the RED concept (i.e., the relative locations of load points with respect to the generator points in open access). The congestion alleviation problem is not formulated as an optimization problem. All generators in the system with sufficient flow margin are subjected to rescheduling of generation process.

The modifications incorporated in the two congestion management methods for comparative study purpose are presented below.

For cluster/zone method [9], generators present in the most sensitive zone (i.e., Zone 1 only) are considered for generation rescheduling. If congestion exists even after 
rescheduling, load curtailment option, as per the indices reported in Ref. [11], is followed. Attractive searching feature of particle swarm optimization (PSO) algorithm is used in this work instead of the GAMS optimization tool. Multiline congestion cases alone are discussed.

For the RED method [10], the required generation change is estimated first. With the new generation change, optimal load flow is run to check whether congestion has been eliminated. If congestion exists, instead of resorting to the procedure again, load curtailment option [11] is followed. Actual contribution of individual generators to loads and line flows are estimated using the method discussed in Ref. [12]. Individual generator contribution is mainly based on the approach described Ref. in [13] that used domains, commons, and links concept. In addition, a set of equations for determining the contribution of individual participants is given in Ref. [14]. In this proposed work, a power flow tracing algorithm that uses the new set of equations based on the concept of dominions and proportional sharing principle is used. The above new set of equations has been formulated based on the ideas proposed in Ref. [15]. Multi-line congestion cases alone are considered.

The comparative study results are illustrated on sample 6-bus system, IEEE 30-bus system, and Indian 69-bus utility system for the assumed operating conditions based on rescheduling cost, generation cost, losses, and voltage stability parameter i.e., $\Sigma L_{j}^{2}$ (sum squared $L$ indices of all load buses $j$ ) and load curtailment option requirement.

\section{Congestion Management Methods: An Overview}

The method of rescheduling of generation based on cluster/zone method [9] and relative electrical distance method $[10]$ is briefly presented in this section.

\subsection{Cluster/Zone-based Method}

The clusters/zones are obtained using $\mathrm{AC}$ transmission congestion distribution factors (ACTCDFs or TCDFs) [9], and these clusters are termed as Types 1, 2, and higher. Type 1 cluster represents users with strongest and nonuniform effects on transmission constraint on interest. The congestion clusters/zones for a multicongestion case can be obtained by superimposing the clusters/zones corresponding to the individual line congestion.

TCDFs are defined as the change in real power flow in a transmission line $k$, connected between bus $i$ and bus $j$ due to unit change in the power injection $\left(\Delta P_{i}\right)$ at bus $i$. Mathematically, the TCDF for the line $k$ can be written as

$$
\operatorname{TCDF}_{i}^{k}=\Delta P_{i j} / \Delta P_{i}
$$

where $\Delta P_{i j}$ is the change in real power flow on line $k$. The TCDFs have been derived using the sensitivity properties of the Newton-Raphson load flow Jacobian.

\subsubsection{Rescheduling of Generation}

In the cluster/zone-based approach, rescheduling is carried out at generators that are present in the sensitive zone only (i.e., Zone 1). The optimal rescheduling of generation problem has been formulated with an objective to minimize the cost for rescheduling subject to the power flow equations, ramp rates of generators, and line flow constraints. The optimization problem is formulated as:

$$
\text { Minimize } \sum_{\substack{i=1 \\ \neq s}}^{N_{G}} C_{i}\left(\Delta P_{i}\right) \Delta P_{i}
$$

Subject to

$$
\begin{gathered}
\sum_{\substack{i=1 \\
\neq s}}^{N_{G}}\left(\left(A C T C D F_{i}^{k}\right) \Delta P_{i}\right)+F_{k}^{0} \leq F_{k}^{\max }, \quad k=1,2 \ldots N_{l} \\
\Delta P_{i}^{\min } \leq \Delta P_{i} \leq \Delta P_{i}^{\max }, i=1,2 \ldots N_{G}, i \neq s \\
P_{i}^{\min } \leq P_{i}+\Delta P_{i} \leq P_{i}^{\max }, \quad i=1,2 \ldots N_{G}, i \neq s \\
P_{G m}-P_{G n}=0 \\
\sum_{m} P_{G m}^{t}-\sum_{n} P_{D n}^{t}=0, \quad t=1,2 \ldots N_{t}
\end{gathered}
$$

where $\Delta P_{i}$ is the real power adjustment at bus $I$ and $C_{i}$ is the incremental or decremental bids submitted by generators, and these are the prices at which the generators are willing to adjust their real power outputs. $N_{\mathrm{G}}$ represents the number of participating generators in the sensitive zone. Eq. (3) is the line flow constraint formed using TCDFs for congested lines. Here, $F_{k}^{0}$ is the power flow caused by all contracts previously settled on line $k$; and $F_{k}^{\max }$ is the line flow limit of line $k$ connecting buses $i$ and $j$. Eq. (4) represents ramp limits for generators. Eq. (5) limits the output of each generator within its maximum and minimum limits. Eqs. (6) and (7) are power flow equations for bilateral and multilateral contracts, respectively; in pool-based market structures, the optimization model will not contain these two equations. The number of lines is denoted by $N_{l}$ and $N_{t}$ represents total number of contracts. The rescheduling problem formulated for congestion management is a nonlinear programming problem and for solving, attractive searching features of PSO. The problem formulation using PSO is given below.

Searching points for rescheduling generation power within generators ramp limits are initialized, satisfying the constraints given by Eqs. (4) and (5). In addition, velocity is generated. The rescheduling cost is determined for all searching agents. If constraints are violated and penalty is 
added to cost; hence, fitness is evaluated for each searching point. Fitness function is an augmentation of objective function and constraint violation with penalty. Initially, all searching agents are taken as $P_{\text {best }}$. Among $P_{\text {best }}$, minimum fitness point is set as $G_{\text {best }}$. New velocities are calculated and new searching points are calculated. Fitness for each searching point is evaluated, and if the new value is better than corresponding $P_{\text {best }}$, it is set as $P_{\text {best }}$. Among the $P_{\text {best }} \mathrm{s}$, minimum fitness point is set as $G_{\text {best }}$. Until maximum iteration is reached, the steps, starting from calculation of new velocities, are repeated. When maximum iteration is reached, the $G_{\text {best }}$ is taken as optimum rescheduling generation power.

\subsection{Relative Electrical Distance Method}

For managing congestion, $F_{L G}$ matrix is first obtained. The relative electrical distance matrix $\left[R_{L G}\right]$ and the matrix $\left[D_{L G}\right]$ for obtaining the desired proportions of generation for the desired load sharing/generation scheduling is also obtained from the $\left[F_{L G}\right]$ matrix as explained in Ref. [10].

The fully loaded and overloaded lines are then identified, and the contribution of each generator to all the congested lines is estimated. Power tracing algorithm is proposed in this work to evaluate individual generators contribution toward loads and line flows instead of domains, commons and links used in Ref. [10]. The generators are classified into two groups (i.e., GI and GD) based on the generator direction of contribution to the congested lines. Generation in GI group of generators is increased, whereas generations are reduced in the GD group. For a given operating condition, the total generation change in GI group must be same as the total generation change in the GD group.

The margin available on the generators of both the groups (GI and GD) is then estimated based on the desired generation schedule. The amount of generation change required to relieve the congestion of the mostly congested line is estimated, after which the total amount of required change is shared by the generators of the GD group in proportion to the margins available on these generators. Similarly, the total generation change of the GI group is shared by the generators in proportion to the margins available on the GI-group generators. With this new generation schedule, the operational load flow should be performed and the presence of congestion should be checked. If congestion still exists, load curtailment option is followed.

\section{Power Tracing Algorithm}

Power tracing algorithm used in this work uses the concept of source dominion and proportional sharing principle to estimate the contribution of generators toward line flows and loads [12]-[14]. Using downstream tracing, information such as to where the electric power of each generator goes and how much each generator shares the power flow in each transmission line can be found. Using upstream tracing, determining where the electric power of each load comes from and how much each load shares the power flow in each transmission line is possible.

The contribution of each dominion to the branch power and load power is determined using the proportional sharing principle. Fig. 1 shows the contributions of active power dominions to branch " $a b$." The power flow at the sending end of line " $a$ " is made up of contribution of the " $n$ " inflows and the generator.

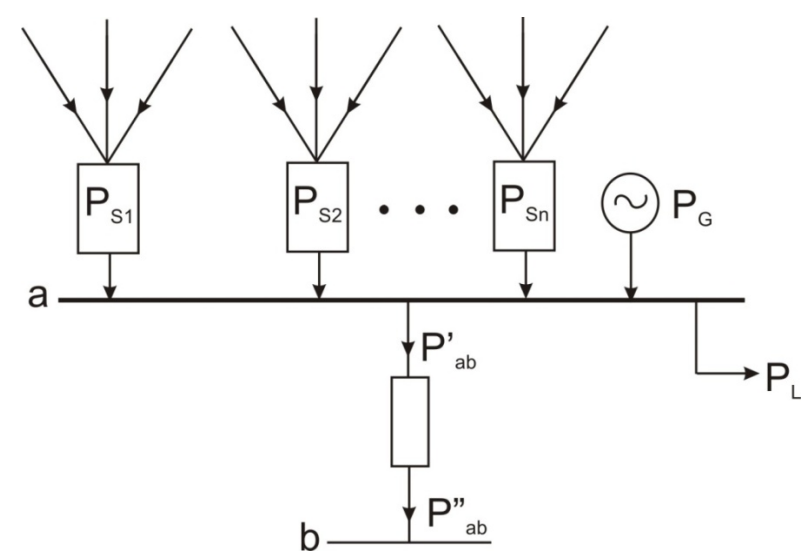

Fig. 1. Contribution of active power dominions to branch " $a b "$

Similarly, the load $P_{L}$ is fed by the contributions of the $n$ inflows and the generator. The following set of equations applies at the sending end of the branch:

$$
\begin{gathered}
P_{a b}^{\prime}=P_{S 1}^{\prime}+P_{S 2}^{\prime}+\ldots .+P_{S n}^{\prime}+P_{G}^{\prime} \\
P_{S i}^{\prime}=P_{S i} \times C_{P_{a b}}^{\prime} \text { where } i=1,2, \ldots, n \\
P_{G}^{\prime}=P_{G} \times C_{P_{a b}}^{\prime}
\end{gathered}
$$

where $C_{P_{a b}}^{\prime}$ is the contribution coefficient and is given by

$$
C_{P_{a b}^{\prime}}^{\prime}=\frac{P_{a b}^{\prime}}{P_{S 1}+P_{S 2}+\ldots .+P_{S n}+P_{G}}
$$

Single prime indicates the sending end. Similarly, the contribution of the $n$ inflows at the receiving end of branch " $a b$ " is also determined by the above equations and is represented by double prime (i.e., $C_{p_{a b}}^{n}, P_{a b}^{*}, P_{S i}^{n}$, and $P_{G}^{n}$ ). In the above expressions, $P_{S i}$ is the power contributions of dominion $S_{i}$ to bus " $a$." The contribution of each dominion contains inflows from each of its branches. If bus " $a$ " is the starting point, then the bus inflow will be $P_{G}$ as opposed to $P_{S i}$. In downstream tracing, contribution coefficients are a fraction of inflow to that bus, whereas, in upstream tracing, they are a fraction of outflow at that bus.

The proportional sharing principle is also used for find- 
ing the contributions of each dominion to the load. Fig. 2 shows the active dominions contributions to load. Load $P_{L}$ is connected at bus " $a$," and the set of equations applied at the load point are given below.

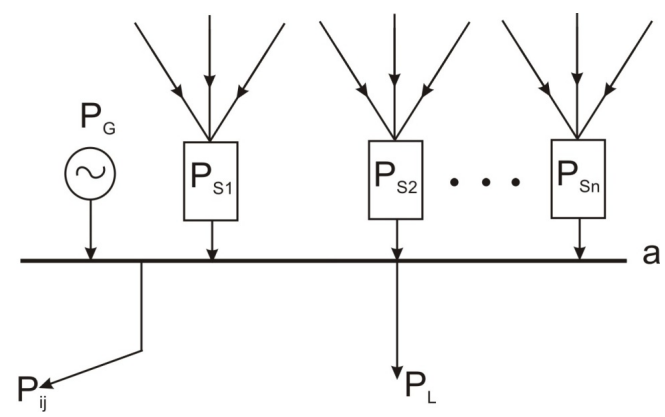

Fig. 2. Active dominions contributions to load

$$
\begin{gathered}
P_{L}=P_{S 1}^{\prime}+P_{S 2}^{\prime}+\ldots .+P_{S n}^{\prime}+P_{G}^{\prime} \\
P_{S i}^{\prime}=P_{S i} * C_{P_{L}} \quad \text { where } i=1 \text { to } n \\
P_{G}^{\prime}=P_{G} * C_{P_{L}}
\end{gathered}
$$

where $C_{P_{L}}$ the contribution coefficient:

$$
C_{P_{L}}=\frac{P_{L}}{P_{S 1}+P_{S 2}+\ldots .+P_{S n}+P_{G}}
$$

\section{Load Curtailment}

A strategy to decide the one most likely volunteer to lower its consumption of electricity when transmission congestion occurs and how much load can be curtailed is to be determined based on simple indices given in Ref. [11]. A brief discussion on these indices is given below.

\subsection{Sensitivity Index}

The sensitivity factors of different locations $(j)$ of the system are ranked by the following index:

$$
\mu_{T j}=\frac{T_{k j}-T^{\min }}{T^{\max }-T^{\min }} \text { for }\left(T^{\min } \leq T_{k j} \leq T^{\max }\right)
$$

Here, $T^{\text {max }}$ is the maximum sensitivity in the system, and $T^{\text {min }}$ is the smallest sensitivity that gives a dead band below which loads with smaller sensitivity will be neglected. The index $\mu_{s}$ is highest at " 1 " for the bus with highest sensitivity and " 0 " for the bus with the smallest sensitivity.

\subsection{Customer Load Curtailment Index}

If the minimum reduction of power flow on the congested branch is given by $\Delta P_{d}$, the required amount of ad- justment at bus $j$ is given by

$$
u_{L j}^{*}=\Delta P_{d} / T_{k j}
$$

Generally, the higher the sensitivity, the smaller the amount of curtailment needed. The customer is supposed to express the acceptable range of curtailment by $u^{\max }$ and $u^{\min }$. The acceptable level is measured by the following index:

$$
\mu_{L j}=\left\{\begin{array}{lc}
1 & \left(u_{L j} \leq u^{\min }\right) \\
\frac{u^{\max }-u_{L j}}{u^{\max }-u^{\min }} & \left(u^{\min } \leq u_{L j} \leq u^{\max }\right) \\
0 & \left(u_{L j} \geq u^{\min }\right)
\end{array}\right.
$$

If the index $\mu_{L j}$ is " 1 ," then the required amount of load curtailment is in the acceptable range of the customer. If $\mu_{L j}$ is " 0 ," then the required amount of load curtailment is higher than the acceptable range and it is not permitted by the customer.

\subsection{Overall Index}

The index $\mu_{C j}$ measures the level of customer incentive to curtail load. If $\mu_{C j}$ is equal to 1.0 , then the customer will have more incentive to curtail load. Assuming this index as 1.0, overall index is given by,

$$
\omega_{L j}=\mu_{T j} \cdot \mu_{L j} \cdot \mu_{C j}
$$

Because all of the individual indices are scaled to values between 0 and 1, the overall index also falls into the range of $0-1$. By calculating the same index for all the buses, the feasibility of congestion management options can be measured by load curtailment.

\section{Parameters Used for Comparison}

Rescheduling cost is the cost for relieving congestion (i.e., the cost for rescheduling generation). Generation cost and losses are calculated for the two methods of congestion management discussed. Moreover, voltage stability assessment is made and compared for the two methods with the use of sum squared $L$ indices calculated for all load buses.

\subsection{Rescheduling Cost}

The rescheduling cost is determined from the increment and decrement bid submitted by each generator. The bid for increment and decrement are assumed to be same. The incremental or decrement bid for each generator is $C_{i}\left(\Delta P_{i}\right)$. 
This bid value is given by the first-order derivative of cost function given by

$$
\frac{d C_{i}}{d P_{i}}=2 a_{i} * P_{i}+b_{i} \quad \text { \$MW-h }
$$

After obtaining the generation rescheduling magnitude, $\Delta P_{i}$, the rescheduling cost is calculated. Eq. (21) is for cluster/zone method. For the RED method, slack bus should be included.

$$
C_{R C}=\sum_{\substack{i=1 \\ \neq s}}^{N_{G}} C_{i}\left(\Delta P_{i}\right) \Delta P_{i} \quad \$ / \mathrm{h}
$$

\subsection{Generation Cost}

Generation cost is obtained from the cost curves of generating units represented by the following equation:

$$
C_{G C}=\sum_{i=1}^{n} C_{i}\left(P_{i}\right)=\sum_{i=1}^{n}\left(a_{i} P_{i}^{2}+b_{i} P_{i}+c_{i}\right) \quad \$ / \mathrm{h}
$$

In the above equation, $a_{i}, b_{i}$, and $c_{i}$ are the cost coefficients of generator $i$; and $P_{G i}$ represents real power generation at generator $i$ after rescheduling.

\subsection{Voltage Stability Assessment}

Voltage stability assessment is made with the help of voltage stability assessment parameter called as $\Sigma L_{j}^{2}$ (sum squared $L$ indices of all load buses $j$ ).

For the given system operating condition, the voltage stability $L$ index [16] is given by:

$$
L_{j}=\left|1-\sum_{i=1}^{g} F_{j i} \frac{V_{i}}{V_{j}}\right|
$$

where $g$ denotes the number of generator buses, $j=g+$ $1, \ldots, n$ represents $(n-g)$ buses, and $n$ is the total number of buses. $F_{j i}$ are the complex elements of $\left[F_{L G}\right]$ matrix. The indicator $L$ is a quantitative measure for the estimation of the distance of the actual state of the system to the stability limit. An $L$ index value away from 1 and close to zero indicates an improved system security.

\section{Results and Discussion}

The simulation studies were carried out on Intel Pentium Dual Core, $2.40 \mathrm{GHz}$ system in MATLAB 7.3 environment.

\subsection{Sample 6-bus System}

Sample 6-bus system is shown in Fig. 3, and the numeri- cal data for the system are taken from Refs. [17].

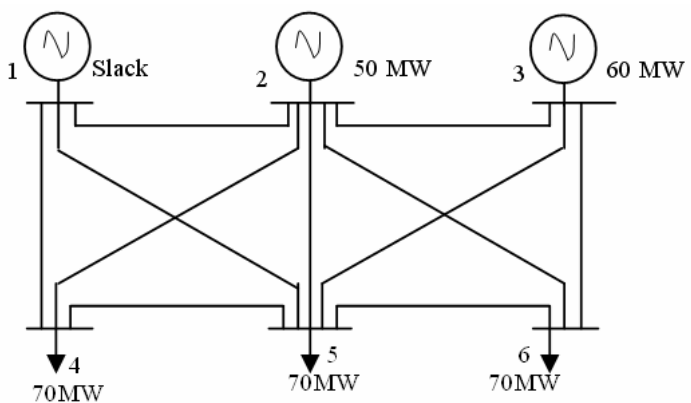

Fig. 3. Sample 6-bus system

Bilateral transaction is carried out between Bus 3 (seller) and Bus 6 (buyer). Repeated AC load flow shows that transaction of $7.5 \mathrm{MW}$ between Buses 3 and 6 results in safer operation. With this normal operation, if the loading of the Buses 4 and 5 is increased by $2 \mathrm{MW}$, congestion occurs. This load increase results in the violation of two line flow limits in Lines 1-2 and 3-5. In Line 1-2, line flow is $30.1231 \mathrm{MW}$ against its limit of $30 \mathrm{MW}$, whereas, in Line 3-5, it is 20.2220 MW against its limit of $20 \mathrm{MW}$.

\subsubsection{Rescheduling of Generation Based on Cluster/Zone Method}

ACTCDFs are determined for the congestion in transmission Lines 1-2 and 3-5. Based on the ACTCDF values, congestion clusters/ zones are formed. Table 1 shows cluster/zone formation due to congestion in the two transmission lines. As per the cluster/zone based approach, rescheduling is carried out in the most sensitive zone only (i.e., Zone 1). For the above-mentioned two-line congestion case, the most sensitive zone can be obtained by superimposing two zone 1s of the congested Lines 1-2 and 3-5, and results in generators connected to Buses 2 and 3 (i.e., $\mathrm{G}_{2}$ and $\mathrm{G}_{3}$ ). Therefore, rescheduling is done on generators $\mathrm{G}_{2}$ and $\mathrm{G}_{3}$ only. The rescheduling problem is formulated using Eqs. (2)-(7), and the minimization problem is solved using PSO algorithm. The PSO parameters are as follows: number of iterations $=100$, number of population $=70$, acceleration factor $C_{1}, C_{2}=1.4$, and maximum and minimum inertia weights are 0.9 and 0.2 . Table 2 shows the generation rescheduling details for generators $G_{2}$ and $G_{3}$

Table 1. Congestion clusters using ACTCDF for sample 6bus system

\begin{tabular}{c|c|c|c|c|c|c|c}
\hline \multicolumn{3}{c|}{ Congestion of Lines 1-2 } & \multicolumn{4}{c}{ Congestion of Line 3-5 } \\
\hline \multicolumn{2}{c|}{ Zone 1 } & \multicolumn{2}{c|}{ Zone 2 } & \multicolumn{2}{c}{ Zone 1 } & \multicolumn{2}{c}{ Zone 2 } \\
\hline Bus & ACTCDF & Bus & ACTCDF & Bus & ACTCDF & Bus & ACTCDF \\
\hline 1 & 0.2396 & 4 & -0.0694 & 2 & -0.0051 & 1 & -0.0717 \\
\hline 2 & -0.2396 & 5 & -0.0917 & 3 & 0.1948 & 4 & -0.0505 \\
\hline 3 & -0.1778 & & & 5 & -0.1948 & 6 & 0.0809 \\
\hline 6 & -0.1872 & & & & & & \\
\hline
\end{tabular}


and the corresponding rescheduling cost.

Table 2. Rescheduling results with cluster/zone method for sample 6-bus system

\begin{tabular}{c|c|c|c|c}
\hline $\begin{array}{c}\text { Genera- } \\
\text { tors }\end{array}$ & $\begin{array}{c}\text { Generation } \\
\text { during conges- } \\
\text { tion, } P_{i}(\mathrm{MW})\end{array}$ & $\begin{array}{c}\text { Rescheduling of } \\
\text { generation re- } \\
\text { quired, } \Delta P_{i}(\mathrm{MW})\end{array}$ & $\begin{array}{c}\text { Generation after } \\
\text { rescheduling } \\
(\mathrm{MW})\end{array}$ & $\begin{array}{c}\text { Resched- } \\
\text { uling cost } \\
(\mathrm{US} \$ / \mathrm{h})\end{array}$ \\
\hline $\mathrm{G}_{2}$ & 50.0000 & $(+) 1.6697$ & 51.6697 & 20.3243 \\
\hline $\mathrm{G}_{3}$ & 67.5000 & $(-) 1.6576$ & 65.8424 & 21.1873 \\
\hline
\end{tabular}

The "+" sign indicates increase in generation required, and the "-" sign refers to decrease in generation required to relieve congestion. With this amount of rescheduling of generation, congestion is completely relieved from the two congested lines. The flow in the Line $1-2$ is $29.9214 \mathrm{MW}$, and is only $19.8976 \mathrm{MW}$ in Line 3-5.

\subsubsection{Rescheduling of Generation Based on RED Method}

From the contributions of individual generators to congested lines, it has been observed that generators $G_{1}$ and $G_{3}$ are contributing to the two congested lines. There is no contribution from the generator $G_{2}$ to the congested lines. Hence, generators $G_{1}$ and $G_{3}$ belong to GD group and the generator $G_{2}$ belongs to GI group. Therefore, generation decrease is recommended at generators $G_{1}$ and $G_{3} G_{3}$, and generation increase is recommended at generator $\mathrm{G}_{2}$.

Flow margin available on the congested lines are to be checked before suggesting the required generation change in the generators. Flow margin available on the line is the difference between the flow suggested by $D_{\mathrm{LG}}$ and actual flow. Sufficient margin is available on these congested lines; thus, excess flow of $0.1231 \mathrm{MW}$ in Line 1-2 and $0.2220 \mathrm{MW}$ in Line $3-5$ can be reduced by suggesting the required generation change on the GD group generators $G_{1}$ and $G_{3}$. Consequently, before suggesting generation change in $\mathrm{G}_{2}$, flow margin in Lines $2-4,2-5$, and 2-6 are to be checked because these are the lines connected to Bus 2 . Because sufficient margin is available on Lines $2-4,2-5$, and 2-6, generation increase can be suggested in $\mathrm{G}_{2}$. Magnitude of generation change in $G_{1}, G_{2}$, and $G_{3}$ are as per the procedure outlined [10]. Table 3 shows the generation rescheduling details and the corresponding rescheduling cost. With this amount of rescheduling of generation, congestion in the two lines has been relieved. The flow in the Line 1-2 is $29.6820 \mathrm{MW}$, and is only 19.9282 MW in Line 3-5.

Table 3. Rescheduling results with RED method for sample 6-bus system

\begin{tabular}{c|c|c|c|c|c}
\hline \multicolumn{2}{c|}{} & $\begin{array}{c}\text { Generation } \\
\text { during } \\
\text { Generators } \\
\text { congestion, } \\
P_{i}(\mathrm{MW})\end{array}$ & $\begin{array}{c}\text { Rescheduling of } \\
\text { generation } \\
\text { required, } \Delta P_{i} \\
(\mathrm{MW})\end{array}$ & $\begin{array}{c}\text { Generation } \\
\text { after } \\
\text { rescheduling } \\
(\mathrm{MW})\end{array}$ & $\begin{array}{c}\text { Rescheduling } \\
\text { cost }(\$ / \mathrm{h})\end{array}$ \\
\hline $\begin{array}{c}\text { GD } \\
\text { group }\end{array}$ & $\mathrm{G}_{1}$ & 112.3491 & $(-) 0.7524$ & 111.5967 & 10.5766 \\
\cline { 2 - 6 } & $\mathrm{G}_{3}$ & 67.5000 & $(-) 1.3573$ & 66.1427 & 17.3609 \\
$\begin{array}{c}\text { GI } \\
\text { group }\end{array}$ & $\mathrm{G}_{2}$ & 50.0000 & $(+) 2.1092$ & 52.1092 & 25.7071 \\
\hline
\end{tabular}

\subsubsection{Comparison Results}

Rescheduling cost, generation cost, power loss, and $L$ index value are calculated for the two methods selected for comparison. Table 4 shows the summary of results for before rescheduling and after rescheduling for the two methods of congestion management.

Table 4. Comparison results for sample 6-bus system

\begin{tabular}{c|c|c|c}
\hline & Before re- & \multicolumn{2}{|c}{ After rescheduling } \\
\cline { 3 - 4 } & scheduling & $\begin{array}{c}\text { Cluster/zone } \\
\text { method }\end{array}$ & RED method \\
\hline $\begin{array}{c}\text { Rescheduling cost }\left(C_{\mathrm{RC}}\right) \\
(\$ / \mathrm{h})\end{array}$ & --- & 41.5116 & 53.6446 \\
\hline $\begin{array}{c}\text { Generation cost }\left(C_{\mathrm{GC}}\right) \\
(\$ / \mathrm{h})\end{array}$ & 3363.5705 & 3458.0171 & 3456.6274 \\
\hline Power loss $(\mathrm{MW})$ & 8.357 & 8.370 & 8.334 \\
\hline$\sum L_{j}^{2}$ value & 0.0964 & 0.0962 & 0.0958 \\
\hline Load curtailment option & - & Not required & Not required \\
\hline
\end{tabular}

\subsection{IEEE 30-bus System}

The numerical data for IEEE 30-bus system is taken from Ref. [18]. There are 6 generators and 41 lines in this system. In this IEEE test system, an outage of Line 4-6 causes congestion on Lines 1-2 and 2-6. The flow in the Line $1-2$ is $132.8870 \mathrm{MW}$ against its limit of $130 \mathrm{MW}$. In the other Line 2-6, it is $69.5312 \mathrm{MW}$ against its limit of 65 MW. This multiple transmission line congestion is eliminated by rescheduling of generation first; and if still congestion exists, load curtailment procedure will be followed.

\subsubsection{Rescheduling of Generation Based on Cluster/Zone Method}

Based on the ACTCDF values, congestion clusters/zones are formed for two congested lines, $1-2$ and 2-6, and the most sensitive zone is obtained by superimposing two zone $1 \mathrm{~s}$, resulting in generators connected to Buses $1,2,5$, and 8 (i.e., $\mathrm{G}_{1}, \mathrm{G}_{2}, \mathrm{G}_{5}$, and $\mathrm{G}_{8}$ ). The generator $\mathrm{G}_{1}$ is slack, and is considered for rescheduling process. The rescheduling magnitudes are $-10.0003 \mathrm{MW}$ for $\mathrm{G}_{1},+7.2809 \mathrm{MW}$ for $\mathrm{G}_{5}$, and $+3.7527 \mathrm{MW}$ for $\mathrm{G}_{8}$. After rescheduling, the line flows are checked in the two congested lines. In Line 2-6, the power flow is 64.325 against its flow limit of $65 \mathrm{MW}$. In Line $1-2$, it is $131.7130 \mathrm{MW}$ against its actual flow limit of $130 \mathrm{MW}$. Clearly, even after rescheduling, congestion condition is not relieved in Line $1-2$. Therefore, load curtailment procedure is followed. Table 5 shows the calculated load curtailment indices for the loads present in the sensitive zone (i.e., Zone 1). Clearly, curtailment of load at Bus 5 relieves congestion more efficiently. The curtailment value is given by $\mu_{L}^{*}$ (i.e., $2.3613 \mathrm{MW}$ ). The flow on the congested line $1-2$ is $129.5123 \mathrm{MW}$, which is lower than the flow limit of $130 \mathrm{MW}$. Therefore, congestion is completely relieved. 
Table 5. Load curtailment indices for IEEE 30-bus system

\begin{tabular}{c|c|c|c|c|c}
\hline $\begin{array}{c}\text { Load } \\
\text { at bus }\end{array}$ & Sensitivity, $T$ & $\begin{array}{c}\text { Sensitivity } \\
\text { index, } \mu_{S}\end{array}$ & $\begin{array}{c}\text { Load curtail- } \\
\text { ment magni- } \\
\text { tude, } \mu_{L}^{*} \\
(\mathrm{MW})\end{array}$ & $\begin{array}{c}\text { Load cur- } \\
\text { tailment } \\
\text { index, } \mu_{L}\end{array}$ & $\begin{array}{c}\text { Overall } \\
\text { index, } \\
\omega_{L}\end{array}$ \\
\hline 2 & 0.863711 & 1.0000 & 2.2875 & 0.6306 & 0.6306 \\
\hline 3 & 0.438970 & 0.0000 & 4.5008 & 0.0000 & 0.0000 \\
\hline 4 & 0.528802 & 0.2115 & 3.7362 & 0.0000 & 0.0000 \\
\hline $\mathbf{5}$ & $\mathbf{0 . 8 3 6 7 1 5}$ & $\mathbf{0 . 9 3 6 4}$ & $\mathbf{2 . 3 6 1 3}$ & $\mathbf{1 . 0 0 0 0}$ & $\mathbf{0 . 9 3 6 4}$ \\
\hline 7 & 0.820923 & 0.8993 & 2.4067 & 0.6296 & 0.5622 \\
\hline 30 & 0.772311 & 0.7848 & 2.5582 & 0.0000 & 0.0000 \\
\hline
\end{tabular}

\subsubsection{Rescheduling of Generation Based on RED Method}

From the contributions of each generator to the congested lines, the congested line 1-2 is fully contributed by $\mathrm{G}_{1}(100 \%)$ and congested line $2-6$ is contributed by $\mathrm{G}_{1}$ $(72.68 \%)$ and $\mathrm{G}_{2}(27.32 \%)$ only. There is no contribution to the congested lines from the other generators connected to buses 5, 8, 11, and 13 (i.e., $\mathrm{G}_{5}, \mathrm{G}_{8}, \mathrm{G}_{11}$, and $\mathrm{G}_{13}$ ). Hence, generators $G_{1}$ and $G_{2}$ belongs to GD group and the remaining generators $\mathrm{G}_{5}, \mathrm{G}_{8}, \mathrm{G}_{11}$, and $\mathrm{G}_{13}$ belong to GI group. Thus, generation decrease is recommended at $\mathrm{G}_{1}$ and

$\mathrm{G}_{2}$ only. Generation increase is recommended in the GI group of generators (i.e., $\mathrm{G}_{5}, \mathrm{G}_{8}, \mathrm{G}_{11}$, and $\mathrm{G}_{13}$ ).

The $D_{\mathrm{LG}}$ matrix is formed, and the desired generation schedule is obtained. The next step is to estimate the margin available in the two generators, $\mathrm{G}_{1}$ and $\mathrm{G}_{2}$. Because the generator $G_{1}$ has maximum impact on the two congested lines, as per the margin available estimation, generation change is not required on generator $\mathrm{G}_{2}$. Therefore, generation is decreased in $\mathrm{G}_{1}$ by $-10.2062 \mathrm{MW}$ and $\mathrm{G}_{2}$ is not disturbed. The actual contribution of the generators in the GI group to the congested lines (in the direction of overload- ing) is zero. Hence, the margin available on these generators $\mathrm{G}_{5}, \mathrm{G}_{8}, \mathrm{G}_{11}$, and $\mathrm{G}_{13}$ are the contributions as per $D_{\mathrm{LG}}$ matrix only. The rescheduling magnitudes are +0.2271 , $+7.7070,+1.3610$, and $+0.9078 \mathrm{MW}$ in the generators $\mathrm{G}_{5}$, $\mathrm{G}_{8}, \mathrm{G}_{11}$, and $\mathrm{G}_{13}$ respectively. Congestion is completely relieved without opting for load curtailment. The summary of results for two methods of congestion management is shown in Table 6.

Table 6. Comparison results of IEEE 30-bus system

\begin{tabular}{|c|c|c|c|c|}
\hline & & \multirow{2}{*}{$\begin{array}{l}\text { Before re- } \\
\text { scheduling }\end{array}$} & \multicolumn{2}{|c|}{ After rescheduling } \\
\hline & & & $\begin{array}{c}\text { Cluster/zone } \\
\text { method }\end{array}$ & $\begin{array}{c}\text { RED } \\
\text { method }\end{array}$ \\
\hline \multicolumn{2}{|c|}{$\begin{array}{c}\text { Rescheduling cost }\left(\mathrm{C}_{\mathrm{RC}}\right) \\
(\$ / \mathrm{h})\end{array}$} & --- & 78.3679 & 71.2786 \\
\hline \multicolumn{2}{|c|}{ Generation cost $\left(C_{\mathrm{GC}}\right)(\$ / \mathrm{h})$} & 2120.5225 & 2131.5548 & 2124.3717 \\
\hline \multirow{2}{*}{$\begin{array}{l}\text { Before load } \\
\text { curtailment }\end{array}$} & $\begin{array}{l}\text { Power loss } \\
\text { (MW) }\end{array}$ & 10.992 & 10.118 & 9.871 \\
\hline & $\sum L_{j}^{2}$ value & 0.1366 & 0.1365 & 0.1359 \\
\hline \multirow{2}{*}{$\begin{array}{l}\text { After load } \\
\text { curtailment }\end{array}$} & $\begin{array}{l}\text { Power loss } \\
\text { (MW) }\end{array}$ & 10.992 & 9.841 & 9.871 \\
\hline & $\sum L_{j}^{2}$ value & 0.1366 & 0.1356 & 0.1359 \\
\hline \multicolumn{2}{|c|}{ Load curtailment option } & - & $\begin{array}{c}\text { Curtailment of } \\
2.3613 \text { MW from } \\
\text { load at bus } 5 \\
\text { required }\end{array}$ & Not required \\
\hline
\end{tabular}

\subsection{Indian 69-bus Utility System}

The bus data and line data are taken from Ref. [19]. This system has 99 lines and 13 generators. TamilNadu is one of the southern states of India, and its system shown in Fig. 4. Bilateral transaction of $50 \mathrm{MW}$ was carried out between Buses 60 (Kundah, Stage 2) and 51 (Arasur), resulting in congestion in Lines 58-56 and 64-65. The flow in Line

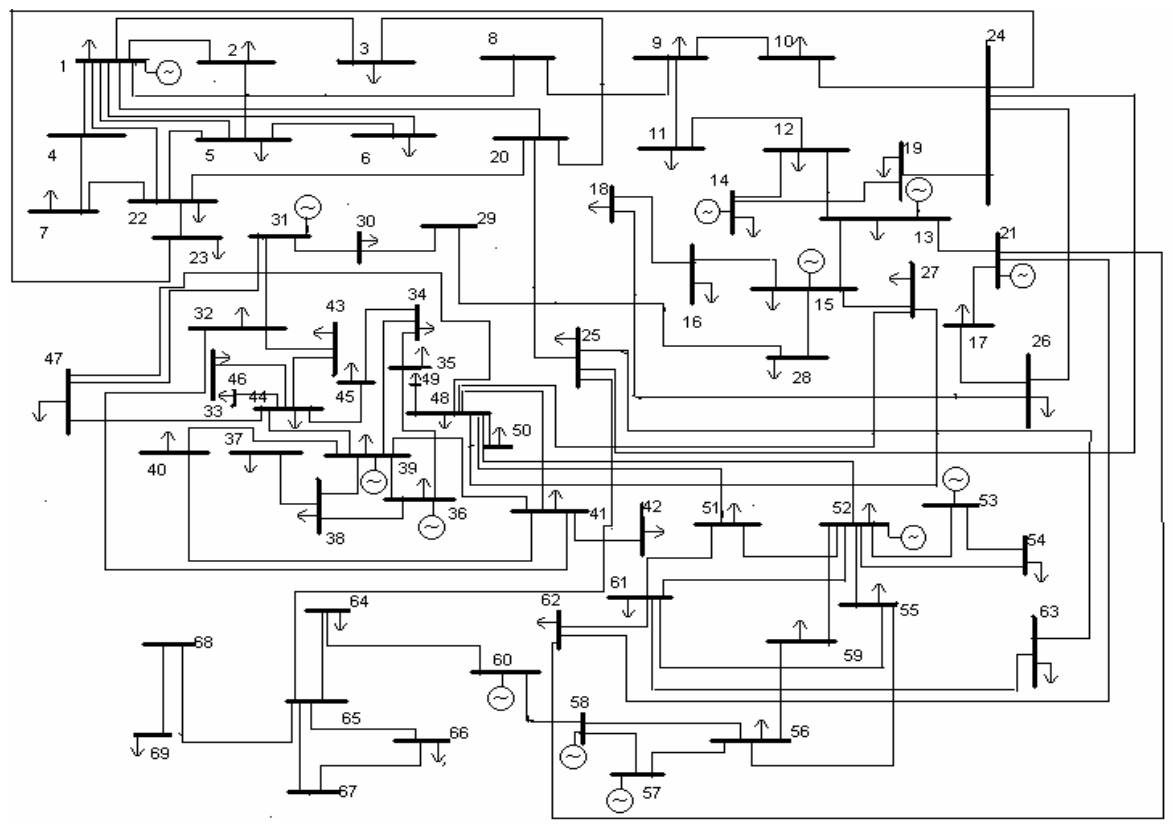

Fig. 4. Indian 69-bus utility system 
58-56 is $161.183 \mathrm{MW}$ against the flow limit of $160 \mathrm{MW}$ in Line $64-65$, whereas it is $90.378 \mathrm{MW}$ against the limit of $90 \mathrm{MW}$.

As per cluster/zone method, rescheduling of generation (i.e., $+4.6956 \mathrm{MW}$ at $\mathrm{G}_{52},+0.2807 \mathrm{MW}$ at $\mathrm{G}_{53},+1.1990$ $\mathrm{MW}$ at $\mathrm{G}_{57}$, and $-5.9384 \mathrm{MW}$ at $\mathrm{G}_{58}$ ) relieves the congestion completely without the need for load curtailment. As per the RED approach, generation increase recommended at the GI group of generators $\mathrm{G}_{1}, \mathrm{G}_{13}, \mathrm{G}_{14}, \mathrm{G}_{15}, \mathrm{G}_{21}$, and $\mathrm{G}_{52}$ is $+0.5830,+0.1721,+0.2000,+0.2000,+1.5093$, and $+1.5450 \mathrm{MW}$, respectively. The generation decrease recommended at the GD group of generators $G_{57}, G_{58}$, and $G_{60}$ is $-2.1322,-1.6360$, and $-0.3071 \mathrm{MW}$, respectively. Generation change is not required in the generators $G_{31}, G_{36}$, $\mathrm{G}_{39}$, and $\mathrm{G}_{53}$.

Table 7 shows the comparison analysis made as per the two congestion management methods (i.e., cluster/zone method and RED method based on the considered parameters).

Table 7. Comparison results for Indian 69 utility bus system

\begin{tabular}{c|c|c|c}
\hline & \multirow{2}{*}{$\begin{array}{c}\text { Before re- } \\
\text { scheduling }\end{array}$} & $\begin{array}{c}\text { Cluster/zone } \\
\text { method }\end{array}$ & RED method \\
\cline { 3 - 4 } & - & 120.2888 & 67.7612 \\
\hline $\begin{array}{c}\text { Rescheduling cost } \\
\left(\mathrm{C}_{\mathrm{RC}}\right)(\$ / \mathrm{h})\end{array}$ & - & 45858.0201 & 45819.0175 \\
\hline $\begin{array}{c}\text { Generation cost } \\
\left(C_{\mathrm{GC}}\right)(\$ / \mathrm{h})\end{array}$ & 45776.6379 & 218.715 & 216.368 \\
\hline Power loss $(\mathrm{MW})$ & 219.061 & 0.5595 & 0.5468 \\
\hline$\sum L_{j}^{2}$ value & 0.5609 & Not required & Not required \\
\hline $\begin{array}{c}\text { Load curtailment } \\
\text { option }\end{array}$ & - &
\end{tabular}

\subsection{Observations from Comparative Study}

The observations made from the comparative study conducted on three test systems are presented below.

In the RED method, the losses are slightly less while simultaneously maintaining good voltage profile and better stability margin. In the cluster/zone method, computing the sensitivity values for all the buses in the system is necessary. If a practical power system with more number of buses is considered, larger amount of computational effort is needed. In addition, based on the sensitivity values, regrouping into various zones consumes more time. However, in the RED method, time taken for congestion relief process is much less.

Rescheduling cost and system cost depends on cost function of each generator, line flow limit, and rescheduling generation magnitudes. From the comparative analysis, except for the small 6-bus system, rescheduling cost is significantly less for RED method since the rescheduling magnitudes are slightly less in the RED method compared to cluster/zone method. For all the test systems considered, generating cost is higher for the cluster/zone method. This is mainly because in the cluster/zone method, generators in the sensitive zone only are subjected to rescheduling process and thereby rescheduling magnitudes in the considered generators are higher. Because the generators in the sensitive zone only are subject to rescheduling in this work, load curtailment option becomes necessary for cluster/zone method, whereas in the RED method, congestion is alleviated in the first attempt itself with minimum effort. Load curtailment option is not necessary for RED method.

The bids of individual generation units and costs of rescheduling are not taken into account in the RED method. Generators having same RED but different price bids must reschedule their outputs in such a way that the total cost of rescheduling is minimal. This problem has not been addressed in the RED method.

\section{Conclusion}

Achieving a commercially transparent and technically feasible solution during transmission congestion poses a great challenge to system operator in the competitive power market. In this paper, two congestion management methods are compared. Both the methods are best suited for the objective of congestion relief. Cost for rescheduling is considered in the cluster/zone method; however, the computational effort and time required is higher. Although congestion relief process is simple and the time factor is minimal in the RED method, rescheduling cost is not considered.

Based on the parameters taken for comparison in this work, and also considering the congestion conditions assumed in the three test systems, the RED-based approach has a slight edge over the cluster/zone method.

\section{References}

[1] R. D. Christie, B. Wollenberg and I. Wangensteen, "Transmission management in the deregulated environment", Proceedings of IEEE, Vol.88, No.2, pp. 170-195, 2000.

[2] A. Kumar, S. C. Srivastava and S.N. Singh, "Congestion management in competitive power market: A bibliographical survey", Electrical Power Systems Research, Vol.76, pp.153-164, 2005.

[3] R. S. Fang and A. K. David, "Transmission congestion management in an electricity market", IEEE Transactions on Power Systems, Vol.14, No.3, pp. 877-883, 1999.

[4] F. Jian and J. W. Lamont, "A combined frame work for service identification and congestion management", IEEE Transactions on Power Systems, Vol.16, No.1, pp.56-61, 2001.

[5] S. Hao and D. Shirmohammadi, "Congestion management with Ex-Ante pricing for decentralized markets", IEEE Transactions on Power Systems, Vol.17, 
No.4, pp. 1030-1036, 2002.

[6] H. Y. Yamina and S. M. Shahidehpour, "Congestion management coordination in the deregulated power market", Electrical Power Systems Research, Vol.65, No.2, pp. 119-127, 2003.

[7] E. Bompard, P. Correia, G. Gross and M. Amelin, "Congestion management schemes: A comparative analysis under a unified framework", IEEE Transactions on Power Systems, Vo1.8, No.1, pp. 346-352, 2003.

[8] B. K. Talukdar, A. K. Sinha, S. Mukhopadhyay and A. Bose, "A computationally simple method for costefficient generation rescheduling and load shedding for congestion management", International Journal of Electric Power and Energy Systems, Vol. 27, No. 5-6, pp. 379-388, 2005.

[9] A. Kumar, S. C. Srivastava and S.N. Singh, "A zonal congestion management approach using ac transmission congestion distribution factors", Electric Power Systems Research, Vol.72, pp.85-93, 2004.

[10] G. Yesuratnam and D. Thukaram, "Congestion management in open access based on relative electrical distances using voltage stability criteria", Electric Power Systems Research, Vol.77, pp. 1608-1618, 2007.

[11] Y. Niu, Y. L. Cong and T. Niimura, "Transmission congestion relief solutions by load management", Proceedings of the IEEE Canadian Conference on Electrical and Computer Engineering, pp.18-23, 2002.

[12] D. Thukaram, H. P. Khincha, B. Ravikumar and G. Yesuratnam, "Generators contribution towards loads and line flows - a case study", IEEE Power India Conference, April, 2006.

[13] D. Kirschen, R. Allan and G. Strbac, "Contribution of individual generators to loads and flows", IEEE Transactions on Power Systems, Vol.12, No.1, pp. 5260, 1997.

[14] E. Acha, C. R. Fuerte-Esquivel, H. Ambriz-Perez and C. Angeles-Camacho, "FACTS Modeling and Simulation in Power Networks", John Wiley publishers, New York, 2004.

[15] J. Bialek, "Tracing the flow of Electricity", Proceedings of IEEE, Vol.143, No.4, pp.313-320, 1996.

[16] P. Kessel and H. Glavitsch, "Estimating the Voltage Stability of a Power System", IEEE Transactions on Power Delivery, Vol. PWRD-1, No.3, pp. 346-354, 1986.

[17] A.J. Wood and B.F. Wollenberg, "Power Generation Operation and Control", John Wiley publishers, New York, 1996.

[18] http://www.ee.washington.edu/research/pstca

[19] Tamil Nadu Electricity Board Statistics at a Glance 2003-2004, Planning Wing of TamilNadu Electricity Board, Chennai, India.

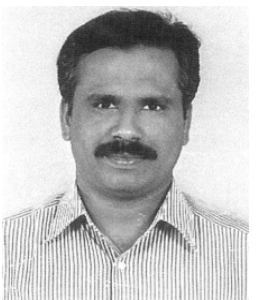

B. V. Manikandan obtained his B.E. degree in Electrical and Electronics Engineering and M.E. degree in Power Systems Engineering in 1992 from Madurai Kamaraj University. $\mathrm{He}$ obtained a Ph.D. degree from Anna University, Chennai, on 2010. His special fields of interest include power system restructuring issues and application of FACTS controllers to power system areas. Presently, he is working as an Assistant Professor in the Electrical and Electronics Engineering department of Mepco Schlenk Engineering College, Sivakasi.

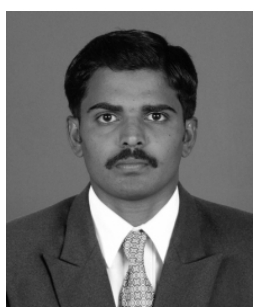

S. Charles Raja is presently working as Assistant Professor in the Electrical and Electronics Engineering department of Thiagarajar College of Engineering, Madurai. He obtained B.E. degree in Electrical and Electronics engineering in 2005 and his M.E. degree in Power Systems Engineering in 2007 from Anna University, Chennai. His topics of interest include power system security, power system optimization techniques, control systems, and application of FACTS controllers.

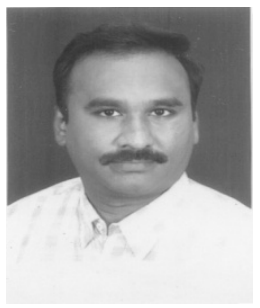

P. Venkatesh received his degree in Electrical and Electronics Engineering and his masters in Power System Engineering with distinction and Ph.D. degree in 1991, 1994, and 2003, respectively, from Madurai Kamaraj University, India. His area of interest is application of evolutionary computation techniques to power system problems and power system restructuring. He has received the Boyscast Fellowship award in 2006 from the Department of Science and Technology, India, for carrying out research work at Pennsylvania State University, USA. Currently, he is an Associate Professor in the Department of Electrical and Electronics Engineering, Thiagarajar College of Engineering, Madurai, India.

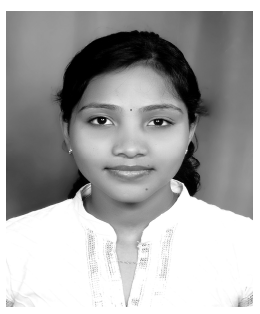

Manasarani Mandala received her B.Tech. degree in Electrical and Electronics engineering from JITS, Karimnagar, India, in 2007, an M.E. degree in Power Systems from Thiagarajar College of Engineering, India, in 2009. Currently, she is a Research Scholar in the Department of Electrical Engineering at the Indian Institute of Technology, Roorkee, India. 